\title{
POLÍTICA MIGRATÓRIA BRASILEIRA E SEUS REFLEXOS PARA OS ESTADOS DA UNASUL: UM ESTUDO A PARTIR DO TRATAMENTO DADO PELO BRASIL AO CASO DOS HAITIANOS*
}

\author{
BRAZILIAN MIGRATION POLICY AND ITS CONSEQUENCES \\ FOR THE STATES OF UNASUR: A STUDY FROM \\ THE TREATMENT GIVEN BY BRAZIL TO THE HAITIAN GASE
}

\author{
Danielle ANNONI** \\ Maria Júlia LIMA MANZI***
}

RESUMO: O presente trabalho visa analisar como os Estados-membros da UNASUL são afetados pela postura brasileira em não reconhecer o status de refugiados os migrantes haitianos após o terremoto que acometeu o país em 2010. Para tanto, são objetivos específicos analisar os argumentos trazidos pela ação civil pública interposta pelo Ministério Público Federal do Acre, em janeiro de 2012 de forma comparativa com a interpretação trazida pelo ACNUR quanto ao conceito de refugiado. A metodologia utilizada será o método dedutivo de analise das fontes, e investigativo documental, quanto ao método de procedimento. A
ABSTRACT: This paper aims to analyze how UNASUR Member States are affected by the Brazilian posture to not recognize the status of refugees to Haitian migrants after the earthquake that struck the country in 2010. Then, specific objectives are to analyze the arguments brought by Public Civil Action filed by federal prosecutors of State of Acre, In Brazil, in Fanuary 2012, comparatively with the interpretation by UNHCR brought about the concept of a refugee. The methodology used is the deductive method of analysis of the sources and investigative documentary, the method of procedure. The central hypothesis of the study focuses on is shown that new categories of refugees should address the role of international protection conferred by existing instru-

* Artículo recibido el 26 de junio de 2015 y aceptado para su publicación el 5 de diciembre de 2015.

** Professora do Programa de Pós-Graduação em Direito da Universidade Federal de Santa Catarina (UFSG/Brasil). Professora de Direito Internacional e Direitos Humanos da Universidade Federal do Paraná (UFPR/Brasil). Titular da Cátedra Sérgio Vieira de Mello do ACNUR-Brasil. Coordenadora do Observatório de Direitos Humanos da UFSC.E-mail: danielle.annoni@ufsc.br.

*** Jornalista, graduada pela Universidade Federal de Santa Catarina (UFSC/Brasil), com Master pela Universidad de Navarra (Espanha)/IICS. Pós-graduada em Comunicação Pública. Graduada em Direito pela UNIVALLI. Membro do Observatório de Direitos Humanos da UFSC.E-mail:juliamanzi@gmail.com.

Boletín Mexicano de Derecho Comparado nueva serie, año XLIX, núm. 146, mayo-agosto de 2016, pp. 61-83.

D. R. C 2016. UNAM, Instituto de Investigaciones Jurídicas. 
Esta revista forma parte del acervo de la Biblioteca Jurídica Virtual del Instituto de Investigaciones Jurídicas de la UNAM

hipótese central do estudo foca-se em se comprovar que novas categorias de refugiados devem abarcar o rol de proteção internacional conferido pelos instrumentos existentes, apontando, no caso dos haitianos, a possibilidade de enquadramento via refúgio ambiental ou "refugiados da fome". As conclusões obtidas são: a) A postura brasileira causa dados em termos de segurança internacional e aumento de crimes internacionais e violência aos Estados-membros que fazem fronteira com o Brasil; b) A ação civil pública brasileira se obtiver êxito fomentará uma releitura do refúgio no continente americano, fortalecendo a integração regional por motivos humanitários.

Palavras-chave: UNASUL. Refugiados. Haitianos. Brasil. Declaração de Cartagena. ments,pointing in the Haitian case, the possibility of framing via environmental refuge or "refugees from hunger". The conclusions are: a) The Brazilian position because data in terms of international security and increased international crimes and violence to bordering with Brazil Member States; b) b) If the Brazilian civil action succeeds, will encourage a rereading of the refuge in the American continent, strengthening regional integration on humanitarian grounds.

SumARIO: I. Introdução. II. Migrantes ambientais ou refugiados? Como a posição brasileira reflete aos demais Estados-membros da UNASUL. III. Migrantes econômicos ou refugiados? A fome como grave e generalizada violação de direitos humanos. IV. Considerações finais. V. Referências das fontes citadas.

\section{INTRODUÇÃO}

Migrar é a regra natural de sobrevivência de todas as espécies e o ser humano não é diferente. O processo de migração na América do Sul, todavia, apesar de existente, nunca foi motivo para preocupações ou atenções por parte dos Estados. Afinal, o número de pessoas que migravam pelos mais diversos motivos não era relevante a ponto despertar políticas direcionadas, construção de programas específicos ou conflitos políticos. ${ }^{1}$

Com efeito, de todos os Estados hoje membros da UNASUL, o Brasil sempre foi o que menos deu importância ao tema. Seja pela questão do idioma, único a falar português num continente de língua espanhola, seja

1 Rocha Reis, R., "A política do Brasil para as migrações internacionais", Contexto Internacional, 33(1), 2011, pp. 47-69. 
Esta revista forma parte del acervo de la Biblioteca Jurídica Virtual del Instituto de Investigaciones Jurídicas de la UNAM

pelas suas dimensões territoriais infinitas; por onde o fluxo migratório que passava não precisava estar incluso na agenda de nenhum governo, não despertava motivos de alarde ou de tomada de decisões. ${ }^{2}$

Ao ratificar a Convenção das Nações Unidas sobre o Estatuto dos Refugiados de 1951, conhecida como Convenção de 1951, seu Protocolo Adicional de 1967, e ingressar no Programa das Nações Unidas para o Reassentamento de Refugiados no início deste século, o Brasil não imaginava ter suas fronteiras abarrotadas de migrantes famintos e desamparados da noite para o dia. Ao contrário, a história já havia comprovado ser o Brasil um país privilegiado, rodeado de fronteiras pacíficas, distante um oceano (ou dois) das guerras centenárias, das zonas de terremotos, vulcões, furacões, tsunamis, longe até mesmo dos novos "bandidos" internacionais: os grupos terroristas e suas milícias separatistas. Com o que mesmo deveria se preocupar? ${ }^{3}$

A chegada de quase 50 mil haitianos no Brasil, ${ }^{4}$ após o terremoto de 2010 ter praticamente devastado aquele país, mudou este quadro. O Brasil, que além de ser Estado parte da Convenção de 1951, assinou e incorporou em lei própria (Lei $n^{\circ}$ 9.474/97) os princípios norteadores da Declaração de Cartagena sobre Refugiados nas Américas, comprometendo-se a acolher refugiados que fogem se deu país também por graves e massivas violações de direitos humanos. ${ }^{5}$

Mas o número de pessoas era muito elevado, e após várias tentativas de negociação com o Alto Comissariado das Nações Unidas para Refugiados - ACNUR, a concessão de um visto humanitário e não o reconhecimento do status de refugiados aos haitianos foi o que resultou. ${ }^{6}$

Com efeito, o terremoto no Haiti provocou inúmeras mudanças regionais, fomentando a necessidade dos Estados afetados definirem novos parâmetros teóricos sobre o tema migrações e, despertando no Brasil, este

2 Jubilut, Liliana Lyra, "Refugee Law and Protection in Brazil: A Model in South America?", Journal of Refugee Studies 19, n. 1, 2006, p. 38.

3 Idem.

4 Levantamento feito pelo demógrafo Duval Fernandes, da Pontifícia Universidade Católica de Minas Gerais (PUC-MG).

5 Fernandes, Jéssica S., Operação Haiti: ação humanitária ou interesse político para o Brasil?, PUC Minas, Conjuntura internacional, 2010, 22 March, pp. 1-4, http:/wrere.pucminas.br/ conjuntura, Accessed 19 April 2011.

6 Patarra, N. L., "O Brasil: país de imigração?”, Metrópolis, Revista Eletrônica de Estudos Urbanos e Regionais, vol. 9, n. 3, 2012, pp. 6-18. 
Esta revista forma parte del acervo de la Biblioteca Jurídica Virtual del Instituto de Investigaciones Jurídicas de la UNAM

país privilegiado de dimensões continentais, cujo discurso diplomático sempre pautou pela solidariedade internacional, pelo respeito aos direitos humanos, pela integração regional a partir de interesses não apenas econômicos, a necessidade de conferir maior destaque ao tema, mais atenção e, por conseguinte, mais preocupações. ${ }^{7}$

O Brasil passou, portanto, a ser observado atentamente pelos seus parceiros, os demais Estados-membros da UNASUL, em especial por não rever sua decisão de conferir aos haitianos o status de refugiado no país. Após várias tentativas de negociação com o Poder Executivo, o Ministério Público Federal do Acre resolveu levar o problema para uma discussão jurídica, propondo uma ação civil pública contra a União Federal. ${ }^{8}$

O objetivo da ação, que está em tramitação, é lograr o reconhecimento do status de refugiado aos haitianos, de modo a coibir o tráfico de pessoas e a exploração de mão de obra no país, situações cada vez mais apontadas e denunciadas pelas organizações não governamentais de direitos humanos, ${ }^{9}$ além de constituir em obstáculo severo para que estas pessoas possam reconstruir suas vidas.

O principal argumento do Ministério Público Federal - MPF, por meio da ação civil pública, concentra-se no fato que, estando a maioria da população haitiana privada do efetivo gozo de seus direitos humanos mais primários - como o direito à alimentação adequada, à água potável, à moradia digna, à saúde e ao acesso ao mercado de trabalho - tal situação representaria uma grave e generalizada violação de direitos humanos, hipótese abarcada pelo art. $1^{\circ}$, III, da Lei n ${ }^{\circ}$ 9.474/97.

Tal interpretação contrasta com a definição do próprio ACNUR, para o qual não se encontram abrangidos pelo instituto de refúgio os casos de vítimas de fome, nem de desastres naturais (ACNUR, 2011:21). A posição do ACNUR a esse respeito faz-se importante porque, apesar do

7 Richman, K., "A more powerful sorcerer: conversion, capital, and Haitian transnational migration", New West Indian Guide, 82(1-2): 3-45, 2008, p. 12.

$8 \mathrm{http} / / \mathrm{g} 1 . \mathrm{globo} . \mathrm{com} / \mathrm{brasil} /$ noticia/2012/01/mpf-entra-com-acao-civil-publica-pedindogarantias-haitianos-no-ac.html. A íntegra da petição inicial e maiores detalhes sobre o processo podem ser acessados no site da Procuradoria Federal do Acre, consultando o Processo 20083000004562 1: http://wrew.prac.mpf.mp.br/atos-do-mpf/acp/acphaitianos/view.

9 O Brasil foi denunciado pela organização Conectas à Comissão Interamericana de Direitos Humanos da OEA (Organização dos Estados Americanos). Sobre o assunto, ver: http://wrere.conectas.org/pt/acoes/politica-externa/noticia/5412-caso-dos-haitianos-chega-a-oea. Acesso em 09.12.13.

D. R. (C) 2016. UNAM, Instituto de Investigaciones Jurídicas, Boletín Mexicano de Derecho Comparado, núm. 146, pp. 61-83. 
Esta revista forma parte del acervo de la Biblioteca Jurídica Virtual del Instituto de Investigaciones Jurídicas de la UNAM

instituto do refúgio estar contemplado em um tratado internacional multilateral com 144 Estados signatários, qual seja, a Convenção de 1951, ${ }^{10}$ a interpretação dos termos deste Tratado é de competência do ACNUR, razão pela qual seu Manual de Procedimentos é utilizado como fonte pelos Estados ao darem início ao procedimento interno de investigação para a concessão do status de refugiados em seus territórios.

Cabe ainda destacar, que o Brasil, e os demais Estados-membros da UNASUL partes da Convenção de 1951, uma vez preenchidos os requisitos dispostos no tratado, não podem furtar-se a cumpri-lo ao argumento de que o número de pessoas que requer acolhida é demasiado ou que os custos não podem ser suportados pelo país. ${ }^{11}$

Uma decisão favorável no caso dos haitianos no Brasil refletiria em todo o continente, ${ }^{12}$ uma vez que o requisito que se discute na ação, qual seja, violação grave e generalizada de direitos humanos, apesar de não explícita na Convenção de 1951, integra de forma expressa a Lei $n^{\circ}$ 9.474/97 13 brasileira, bem como a Declaração de Cartagena, que no ano de 2014 completou 30 anos fomentando a solidariedade internacional em matéria de acolhida de refugiados no continente americano. ${ }^{14}$

10 Informações sobre os Estados signatários da Convenção de 1951 e do Protocolo de 1967 e sua distribuição geográfica, vide https://treaties.un.org/pages/ViewDetailsII.

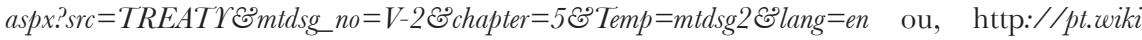
pedia.org/wiki/Conven $\% C 3 \% A 7 \% C 3 \% A 30 \_d a s \_N a \% C 3 \% A 7 \% C 3 \%$ B5es_Unidas_relativa_ao_ Estatuto_dos_Refugiados.

11 Savabi, Heidi, "The Legal Framework and Institutional Assistance for Refugees in Brazil since the Mid-Twentieth Century: The Impact on Refugee Integration and Assistance", IMTP-Magazine on Migration Issues, 2014, p. 23.

12 Apenas a Venezuela, dentre os Estados-membros da UNASUL, não ratificou a Convenção de 1951, embora tenha ratificado o Protocolo de 1967. Fonte: https://treaties.un.org/

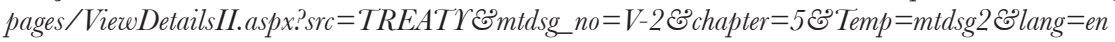

13 O refúgio, por sua vez, conforme a definição trazida pelo art. $1^{\circ}$ da Lei n ${ }^{\circ}$ 9.474/97, é a proteção dada aos indivíduos que... I - devido a fundados temores de perseguição por motivos de raça, religião, nacionalidade, grupo social ou opiniões políticas encontre-se fora de seu país de nacionalidade e não possa ou não queira acolher-se à proteção de tal país; II - não tendo nacionalidade e estando fora do país onde antes teve sua residência habitual, não possa ou não queira regressar a ele, em função das circunstâncias descritas no inciso anterior; III - devido a grave e generalizada violação de direitos humanos, é obrigado a deixar seu país de nacionalidade para buscar refúgio em outro país.

14 Todos os Estados-membros da UNASUL assinaram a Declaração de Cartagena, e no ano em que o instrumento comemorou 30 anos, 14 foram os Estados americanos que se comprometeram a incorporar seus princípios em sua legislação nacional. Fonte: http:// 
Esta revista forma parte del acervo de la Biblioteca Jurídica Virtual del Instituto de Investigaciones Jurídicas de la UNAM

Neste sentido, o presente artigo visa analisar de modo comparativo os argumentos trazidos nessa ação civil pública com as disposições dispostas no Manual de Procedimentos e Critérios para Determinar a Condição de Refugiado do ACNUR, neste trabalho referido como Manual de Procedimentos, produzido em 2011, analisando a possibilidade jurídica de concessão do status de refugiado aos haitianos. A importância deste estudo centra-se nos reflexos regionais que trará, tornando o Brasil paradigma para os demais Estados-membros da UNASUL, no que tange a aplicação dos princípios gerais de respeito aos direitos humanos e a solidariedade internacional em casos concretos.

\section{MigRANTES AMBiENTAIS OU REFUGIADOS? COMO A POSIÇÃO BRASILEIRA REFLETE AOS DEMAIS ESTADOS-MEMBROS DA UNASUL}

Nos últimos anos, muitos são os doutrinadores que têm defendido o enquadramento no status de refugiado daqueles que, em decorrência de desastres ambientais - às vezes potencializados por atividades humanas - precisam deixar o local em que vivem, já que o mesmo se tornou inóspito à vida e à dignidade humana. Diante da ausência de definição jurídica acerca desse grupo de migrantes, o Programa das Nações Unidas para o Meio Ambiente (PNUMA) ${ }^{15}$ formulou uma definição social humanitária para migrantes e deslocados ambientais, nos seguintes termos:

As pessoas que foram obrigadas a abandonar temporária ou definitivamente a zona onde tradicionalmente vivem, devido ao visível declínio do ambiente, por razões naturais ou humanos, perturbando a sua existência e/ou qualidade do mesmo de tal maneira que a subsistências dessas pessoas entrem em perigo. Com o declínio do ambiente quer se dizer, o surgimento de uma transformação no campo físico, químico e/ou biológico do ecossistema, que, por conseguinte, fará com que esse meio ambiente temporária ou permanentemente não possa ser utilizado. ${ }^{16}$

wrwe.onu.org.br/trinta-anos-apos-declaracao-de-cartagena-para-os-refugiados-onu-inicia-consulta-sobre-o-temal.

15 http://wrew.pnuma.org.br/.

16 Zeferino, Marco Aurélio y Pieri, Aguado, "Juventude de Castro. Os deslocamentos ambientais para o Brasil", Revista SfR7, Rio de Faneiro, vol. 19, n. 35, pp. 213-230, dez. 2012, p. 223 .

D. R. (C) 2016. UNAM, Instituto de Investigaciones Jurídicas,

Boletín Mexicano de Derecho Comparado, núm. 146, pp. 61-83. 
Esta revista forma parte del acervo de la Biblioteca Jurídica Virtual del Instituto de Investigaciones Jurídicas de la UNAM

No entanto, essa definição é meramente propositiva, deixando as pessoas que se encontram nessa situação em um verdadeiro limbo jurídico, recorrendo, usualmente, ao princípio do non refoulement ${ }^{17}$ para não serem rechaçados ou enviados de volta ao seu Estado de origem. No caso em tela, os haitianos poderiam ser considerados migrantes ambientais por excelência, uma vez terem sido vítimas de um grande número de desastres naturais que constantemente ameaçaram e ameaçam a parca estrutura que, entre um evento e outro, se consegue edificar no país. Há dezenas de anos Haiti é atingido por furacões e tempestades tropicais que deixam dezenas de mortos e milhares de desabrigados ${ }^{18}$ o que o torna um Estado impossibilitado de garantir as mínimas condições de sobrevivência e dignidade a sua população. ${ }^{19}$

Dentre esses desastres, o mais dramático ocorreu em janeiro de 2010, quando um terremoto de grande magnitude destruiu a capital Porto Príncipe, provocou a morte de quase 300 mil pessoas e deixou pelo menos um milhão de desabrigados. A catástrofe também provocou a ruína da já parca estrutura do país, tornando inutilizáveis nada menos que 300 mil residências, 1300 estabelecimentos escolares e 50 hospitais e centros de saúde, que ruíram. Calcula-se que três milhões de pessoas tenham sido afetadas diretamente. O tremor deu origem, ainda, a um grande deslocamento interno. Mais de 661 mil haitianos

17 Não devolução numa tradução mais simples, implica no principal pilar jurídico do Direito Internacional dos Refugiados, impedindo os Estados signatários de devolver um ser humano que solicita refugio até a comprovação ou não de sua condição. A partir do Plano de Ação do México (2004), o princípio do non refoulement passou a ser reconhecido como norma de jus cogens, devendo ser respeitada também pelos Estados não signatários da Convenção de 1951 e outros tratados internacionais de proteção aos refugiados e migrantes. Paula, Bruna Vieira de, "O princípio do non-refoulement, sua natureza jus cogens e a proteção internacional dos refugiados”, Corte Interamericana de Direitos Humanos, 2006. Acesso em 11/09/2014. http://wwre.corteidh.or.cr/tablas/r28151.pdf.

18 Após o terremoto de 2010, dois foram os principais desastres naturais a fazer vítimas no país: o furacão Sandy, em outubro de 2012, que matou 44 pessoas e causou importantes danos à agricultura; e a tempestade Isaac, em agosto de 2012, que deixou cinco mil desabrigados. Sobre o assunto, destaca-se as seguintes matérias jornalísticas: http://veja.abril.com. $\mathrm{br} /$ noticia/internacional/furacao-sandy-mata-59-no-caribe-e-segue-para-eua, http://wrwrevvalor.com.br/ internacional/2803492/tempestade-isaac-mata-seis-pessoas-no-haiti

19 Thomaz, Diana Zacca, "Migração haitiana para o Brasil pós-terremoto: indefinição normativa e implicações políticas", Primeiros Estudos, São Paulo, n. 4, 2013, p. 131 143 .

D. R. C 2016. UNAM, Instituto de Investigaciones Jurídicas, Boletín Mexicano de Derecho Comparado, núm. 146, pp. 61-83. 
Esta revista forma parte del acervo de la Biblioteca Jurídica Virtual del Instituto de Investigaciones Jurídicas de la UNAM

deixaram os locais afetados para buscar abrigo em outras partes do país, especialmente na fronteira com a República Dominicana.

Importante destacar, todavia, que antes mesmo do terremoto, a situação do país mais pobre das Américas já era desoladora. Cerca de 80\% dos haitianos já vivia abaixo da linha da pobreza, a esmagadora maioria não tinha acesso a serviços essenciais, como água ou energia elétrica e o desemprego já oprimia 70\% da população. O Estado mais pobre do continente, apesar de constituir-se como Nação independente desde 1804, tem nas desigualdades sociais a origem do fenômeno migratório. Tais disparidades podem ser resumidas em dois fatores complexos: a herança colonialista e sua ideologia europeia-crista que potencializaram o racismo e o instituíram como divisor de estratos sociais e políticos. Assim, o Haiti nasceu dividido entre analfabetos e letrados; entre os habitantes da capital Porto Príncipe e os camponeses; entre os falantes do idioma francês e do kreyòl; e entre os vodu e o catolicismo/protestantismo. ${ }^{20}$

A falta de estabilidade política, resultado principalmente da luta pelo poder entre grupos negros e mulatos, a sucessão de ditadores que provocaram a morte e perseguição de dezenas de milhares de opositores, as diversas interferências externas já sofridas, além de embargos econômicos, também contribuíram tanto para aumentar a pobreza, quanto para desestabilizar o país e provocar emigrações. Por todas essas razões, os haitianos tradicionalmente constituem um povo com tendências migratórias. ${ }^{21}$

Desde a década de 50, pelo menos dois milhões de haitianos deixaram o país, rumo, principalmente, à vizinha República Dominicana

20 "De acordo com Aimé Césaire, a idéia do negro bárbaro é uma invenção europeia e, portanto deve ser amplamente problematizada, tanto do ponto de vista histórico quanto da história dos conceitos que gravitaram em torno das nações negras, já que os condicionamentos ideológicos do racismo e do colonialismo impulsionaram inúmeros intelectuais a forjarem uma visão de mundo do Haiti inscrita a partir da selvageria e da barbárie, fundamentadas, sobretudo a partir da idéia de raça". Rosa, Renata de Melo, "A Construção da desigualdade no Haiti: experiências históricas e situações atuais", Revista Universitas: Relações Internacionais, vol. 4, n. 2, 2006, pp. 160-185.

21 "Pelo fato de o Haiti ocupar a posição de país mais pobre das Américas, as chances reais de ascensão social estão localizadas fora da nação. A reprodução da desigualdade incide com muita ênfase nos grupos mais aptos à migração e nas escolhas das rotas migratórias". Rosa, Renata de Melo, "A Construção da desigualdade no Haiti: experiências históricas e situações atuais", cit. 
Esta revista forma parte del acervo de la Biblioteca Jurídica Virtual del Instituto de Investigaciones Jurídicas de la UNAM

e aos EUA. ${ }^{22} \mathrm{O}$ grupo formado pelos emigrantes é tão grande, que se tornou comum fazer referência a um "décimo primeiro departamento" - apesar do Haiti ser dividido em apenas dez - formado pelas comunidades no exterior. ${ }^{23} \mathrm{O}$ dinheiro enviado por esses emigrantes ao país também constitui importante fonte de receita para a economia local, já que todos os anos o Haiti recebe cerca de dois bilhões de dólares em transferências de nacionais que vivem alhures.

Apesar de historicamente a rota migratória dos haitianos se dirigir, sobretudo, aos Estados Unidos, onde vivem cerca de um milhão de cidadãos daquele país; ao Canadá, República Dominicana e França, recentemente o Brasil passou a integrar o rol de destinos preferenciais. Isso porque a postura dos países desenvolvidos diante do desastre natural ocorrido em 2010 no Haiti foi o de fechamento das fronteiras diante da constatação de que a catástrofe daria início a um verdadeiro êxodo. Além do endurecimento das políticas migratórias levados a cabo pelos países desenvolvidos - inclusive com a deportação, por parte dos EUA e da República Dominicana, de centenas de haitianos que haviam ingressado nesses países para receber tratamento médico emergencial devido ao terremoto-, o fato do Brasil ter sido destaque internacional, especialmente por ter sediado recentemente importantes eventos internacionais também contribuiu para essa mudança de roteiro. Arruda destaca, ainda, o peso que a liderança brasileira do braço militar da MINUSTAH teria nesse processo:

A presença da MINUSTAH no Haiti pode ter gerado uma impressão de crescimento e desenvolvimento do Brasil, como uma localidade que apresenta boas oportunidades de estabelecimento econômico, no mercado de trabalho mais diretamente, atraindo números mais significativos de haitianos para seu território.

Uma missão de paz liderada por um país gera não apenas simbolicamente poder perante os demais países do cenário internacional, mas tam-

22 Martin, P. et al., "Migration and development: whiter the Dominican Republic and Haiti?", International Migration Review, Center for Migration Studies of New York, 36 (2), 2002, pp. 570-592.

23 Télémaque, Jenny, Imigração haitiana na mídia brasileira: entre fatos e representações, Rio de Janeiro, 2012, p. 36. 
Esta revista forma parte del acervo de la Biblioteca Jurídica Virtual del Instituto de Investigaciones Jurídicas de la UNAM

bém responsabilidades e imaginários de desenvolvimento econômico do país. ${ }^{24}$ Embora não se possa, pois, atribuir exclusivamente ao terremoto a condição de miserabilidade de grande parte da população do Haiti, o desastre natural com certeza agravou o já complicado quadro, de tal forma que, quatro anos depois e apesar do auxílio internacional, a situação da população pouco mudou, dependendo das organizações internacionais e da MINUSTAH, ${ }^{25}$ para conseguir desde água até empregos. Há, no país, nada menos que 325 projetos de ONGs que trabalham no sistema de voluntariado, razão pela qual Thomaz afirma que "não há nada neste país... que seja feito independentemente da tutela das grandes organizações internacionais". ${ }^{26}$ Ao que Seitenfus acrescenta: “...as Ongats são bem mais do que um Estado dentro do Estado. No Haiti elas são o Estado". ${ }^{27}$ As Organizações não-governamentais têm, pois, tentado substituir um governo que parece não ter se reerguido após o desastre natural.Com efeito, o caso haitiano não é um caso isolado. Segundo dados da Universidade das Nações Unidas (UNU), Ramos ${ }^{28}$ destaca que, em 2010, calculava-se que, em todo mundo, havia cerca de 50 milhões de pessoas forçadas a deixar seu país por razões ambientais, e a UNU estima que, até o ano de 2050, cerca de 200 milhões de pessoas terão tido que abandonar seus lares em razão de processos de degradação e desastres ambientais. E conclui que, "hoje já se reconhece que os deslocamentos humanos vinculados a grandes projetos de desenvolvimento e a desastres naturais ocorrem de cinco a dez vezes mais do que os deslocamentos gerados por conflitos". ${ }^{29}$

24 Arruda, Aline Maria Thomé, "Migração e refúgio: uma breve problematização sobre os direcionamentos governamentais para recepção a haitianos no Brasil e na República Dominicana”, Universitas Relações Internacionais, Brasília, vol. 11, n.1, jan./jun. 2013, pp. 109 y 110.

25 Missão das Nações Unidas para Estabilização do Haiti iniciada em 2004 e, desde então, comandada militarmente pelo Brasil, o que despertou o interesse dos haitianos no Brasil, uma vez que sua rota de migrações sempre se concentrou na América Central e do Norte. http://wrew.minustah.org/.

26 Thomaz, Omar Ribeiro, "O terremoto no Haiti, o mundo dos brancos e o Lougawou”, Novos Estudos, São Paulo, vol. 1, n. 86, mar. 2010, p. 24.

27 Seitenfus, Ricardo, Haiti: dilemas e fracassos internacionais, Ijuí: Unijuí, 2014, p. 271.

28 Ramos, E., Refugiados ambientais: em busca de reconhecimento pelo direito internacional, tese (doutorado em direito), Faculdade de Direito, Universidade de São Paulo, São Paulo, 2011 , p. 11.

29 Idem.

D. R. (C) 2016. UNAM, Instituto de Investigaciones Jurídicas,

Boletín Mexicano de Derecho Comparado, núm. 146, pp. 61-83. 
Esta revista forma parte del acervo de la Biblioteca Jurídica Virtual del Instituto de Investigaciones Jurídicas de la UNAM

Ainda que a própria Organização das Nações Unidas (ONU) e ACNUR reconheçam esses dados alarmantes, essa categoria específica de refugiados permanece sem o devido reconhecimento pelo Direito Internacional, por não estar compreendida no conceito tradicional de refugiado da Convenção de 1951, ${ }^{30}$ nem no Protocolo de 1967. ${ }^{31}$ Mais grave do que isso. Não apenas não são reconhecidos como refugiados. Como explica Ramos:

Tanto a Convenção relativa ao Estatuto dos Refugiados - que não possui um mandato ambiental-, bem como a Convenção sobre Mudança Climática - que não é centrada na proteção dessa nova categoria de pessoas, tampouco nos processos de restauração ecológica-, apresentam limitações para lidar com as novas situações jurídicas advindas do reconhecimento de uma nova categoria de refugiados. ${ }^{32}$

O ACNUR apesar de estar monitorando dados referentes a pessoas que se encontram nessa situação é contrário a que lhes seja concedido o status de refugiados. Desta forma, seu Manual de Procedimentos afirma expressamente que entre os refugiados, “...não estão abrangidos os casos de vítimas de fome ou de desastres naturais, a menos que também receiem com razão a perseguição por um dos motivos referidos". ${ }^{33}$ Essa última hipótese se justifica porque, por vezes, o impacto das mudanças climáticas e a ocorrência de desastres naturais podem contribuir para acentuar confli-

30 Ocorrida em Genebra, a Convenção definia refugiado, em seu art. 1o. A (2) como sendo: "Para os fins da presente Convenção, o termo refugiado aplicar-se-á a qualquer pessoa que, em consequência de acontecimentos ocorridos antes de 1o. de janeiro de 1951, e receando com razão ser perseguida em virtude de sua raça, religião, nacionalidade, filiação em certo grupo social ou das suas opiniões políticas, se encontre fora do país de que tem nacionalidade, e não possa ou, em virtude daquele receio, não queria pedir a proteção daquele país; ou que, se não tiver nacionalidade e estiver fora do país no qual tinha a sua residência habitual após aqueles acontecimentos, não possa ou, em virtude do dito receio, a ele não queira voltar".

31 O Protocolo de 1967 ampliou a definição de refugiado trazida pela Convenção de 1951, eliminando a limitação de datas e de espaço geográfico.

32 Ramos, E., Refugiados ambientais: em busca de reconhecimento pelo direito internacional, pp. 18 y 19 .

33 Manual de procedimentos e critérios para a determinação da condição de refugiado, disponível em http://wrwe.acnur.org/t3/fileadmin/scripts/doc.php?file $=t 3 /$ fileadmin/Documentos/ portugues/Publicacoes/2013/Manual_de_procedimentos_e_criterios_para_a_determinacao_da_condi cao_de_refugiado, p. 21. 
Esta revista forma parte del acervo de la Biblioteca Jurídica Virtual del Instituto de Investigaciones Jurídicas de la UNAM www.juridicas.unam. $\mathrm{mx}$

tos e intensificar a competição por recursos que, devido àqueles acontecimentos, se tornam escassa. ${ }^{34}$

O ACNUR reconhece a existência de categorias de migrantes que necessitam de ajuda humanitária, mas, por estarem fora do âmbito de proteção internacional, não são beneficiados com assistência. Já o Ministério Público Federal brasileiro acredita que deva ocorrer no Brasil esta inclusão, uma vez que não há impedimento legal para que os Estados ampliem a interpretação dada pelo ACNUR aos instrumentos normativos de proteção aos direitos humanos na ordem global. ${ }^{35}$

Além disso, o não reconhecimento dos refugiados ambientais, segundo $\operatorname{Ramos}^{36}$ favorece a imigração ilegal, o tráfico internacional de pessoas e o aliciamento para atividades criminosas, situações de flagrante violação de direitos humanos que são reflexo direto da indefinição jurídica em que se encontram.

É o que vem ocorrendo a partir da postura do Brasil, conforme aponta a os dados reunidos na ação civil pública citada. Redes criminosas que intermedeiam a imigração ilegal passaram a atuar no Brasil e em outros Estados-membros da UNASUL, com a utilização de "coiotes" para tra-

34 O ACNUR tem receio de que, reunir os 144 Estados atualmente signatários da Convenção de 1951 para discutir reformas no instrumento internacional, com vistas a incluir novas categorias, tenha efeito contrário. Uma vez reunidos e estando o instrumento internacional novamente "aberto" a negociações, nada garante que os Estados, os invés de ampliar, não criarão restrições ainda maiores ao instituto do refúgio. Em tempos de crise, o posicionamento dos Estados frente ao movimento migratório de estrangeiros é retrogrado e o instrumento hoje se encontra legitimado pela esmagadora maioria dos Estados. O ACNUR defende um novo tratado internacional, com vistas à proteção de migrantes ambientais e deslocados de Estados falidos e zonas de difícil sobrevivência com dignidade, mas os Estados são contrários a criação de um instrumento internacional dessa natureza, por acreditarem que estariam reconhecendo, ao reconhecerem refugiados de determinada localidade, os desastres ambientais praticados neste lugar, com conseqüências já determinadas em outros tratados internacionais de âmbito ambiental. http://www.acnur.org/t3/portugues/. Ramirez, A., "ONU pede mais proteção para refugiados ambientais: entrevista". Observatório Eco. [25 de maio, 2012]. Disponível em wrwe.observatorioeco.com.br/onu-pede-mais-protecao-para-refugiados-ambientais $/+\mathcal{E}^{2} c d=3 E^{2} h l=p t$ $-B R \mathcal{E}^{2} c t=c \ln k \mathcal{E}^{2} g l=b r \mathcal{E}^{2} l r=l a n g \_f r \% 7 C l a n g \_e n \% 7 C l a n g \_p t>$. Acesso em 08/02/2014.

35 Pentinat, S. B., "El Estatuto jurídico de protección internacional de los refugiados ambientales", Revista Interdisciplinar da Mobilidade Humana, n. 19, 201 1, p. 48.

36 Ramos, E., Refugiados ambientais: em busca de reconhecimento pelo direito internacional, p. 18.

D. R. (C) 2016. UNAM, Instituto de Investigaciones Jurídicas,

Boletin Mexicano de Derecho Comparado, núm. 146, pp. 61-83. 
Esta revista forma parte del acervo de la Biblioteca Jurídica Virtual del Instituto de Investigaciones Jurídicas de la UNAM

vessia de fronteiras, rotas ilegais que expõem os migrantes a todo tipo de perigo, além de diversas denúncias de abuso sexual inclusive de adolescentes e crianças, durante o trajeto. ${ }^{37}$

Como colocado pela ação civil pública:

Em segundo lugar, o Estado acaba por colocar os imigrantes haitianos em estado de clandestinidade, aumentando ainda mais o estado de vulnerabilidade no qual eles já se encontram... ao proibir tal ingresso, nossa república incentiva a busca de caminhos ilegais por parte dos haitianos, que passam a pedir ajuda a coiotes (os quais normalmente abusam da condição vulnerável dos refugiados) para serem introduzidos ilegalmente no país.

É preciso observar que a migração haitiana é uma realidade atual que não irá ser estancada por meio de uma tentativa de fechamento das fronteiras pelo Brasil. Os haitianos se movem hoje por necessidade extrema de subsistência e não por mero capricho. ${ }^{38}$

O Ministério Público Federal ressalta, ainda, que dada a grande extensão da fronteira brasileira, praticamente todos os Estados-membros da UNASUL são afetados pela postura brasileira, por se constituírem em rota de passagem das organizações criminosas. Assim, sem o devido reconhecimento jurídico, os haitianos veem-se obrigados a viver na clandestinidade em território brasileiro, sujeitando-se a diversas formas de exploração, como o trabalho escravo, infantil, prostituição, tráfico de órgãos, tráfico de pessoas, tráfico de drogas e armas, filiação compulsória a grupos terroristas e de milícias armadas, cuja atuação compromete a segurança regional e outros projetos de integração Sul-americana. ${ }^{39}$

Com efeito, a postura do Brasil em negar reconhecimento de refugiados aos haitianos tem consequências perversas para toda a integração regional, uma vez que Estados como o Equador e a Bolívia tem fomentado políticas públicas de acolhimento a migrantes ambientais, e negociado convênios internacionais de assistência humanitária para

37 Zolberg, A. R e Benda, P. M., Global Migrants, Global Refugees: Problems and Solutions, Washington (D. C.), Berghahm Books, 2001, p. 34.

38 MPF/Acre, Processo 200830000045621: http://wrew.prac.mpf.mp.br/atos-do-mpf/acp/ acphaitianos/view, petição inicial, p. 23.

39 Tamer, Alexandre dos Santos y Pozzeti, Valmir César, "A imigração haitiana e a criminalidade no município de Manaus", Revista do Direito Público, Londrina, vol. 8, n. 3, pp. 55-76, set./dez. 2013. 
Esta revista forma parte del acervo de la Biblioteca Jurídica Virtual del Instituto de Investigaciones Jurídicas de la UNAM

todas as categorias de migrantes, em plano de igualdade de tratamento e de direitos. ${ }^{40}$

\section{MigRAntes EGONÔMICOS OU REFUgiados? A FOME COMO GRAVE E GENERALIZADA VIOLAÇÃO DE DIREITOS HUMANOS}

O argumento central da ação civil pública proposta pelo Ministério Público Federal do estado do Acre é de que, “...não estando migrando para o Brasil por outro motivo que não a extrema necessidade de buscar uma vida mais digna, de fugir de uma situação de absoluta privação dos direitos humanos mais básicos...", ${ }^{41}$ tal situação configuraria grave e generalizada violação de direitos humanos, configurando a hipótese do inciso III, do art. $1^{\circ}$ da Lei $n^{\circ}$ 9.474/97. Nesse sentido, Trindade destaca que:

A pobreza crônica não é uma fatalidade, mas materialização atroz da crueldade humana. Os Estados são responsáveis pela observância da totalidade dos direitos humanos, inclusive os econômicos e sociais. Não há como dissociar o econômico do social e do político e do cultural. ${ }^{42}$

Considerando que, atualmente, há no mundo mais de 850 milhões de pessoas subnutridas, ${ }^{43}$ alguns doutrinadores recentemente passaram a reconhecer o chamado "refugiado econômico", definido por Casella ${ }^{44}$ como aquele que "se vê diante da impossibilidade total de satisfazer suas necessidades vitais no país do qual é nacional". O mesmo autor diferencia o refugiado econômico do migrante econômico que poderia subsistir em seu país natal, mas busca melhores perspectivas em outra região. Como

40 Silva, Sidney Antonio, "Brazil, a New Eldorado for Immigrants?: The Case of Haitians and the Brazilian Immigration Policy", Urbanities, vol. 3, n. 2, november, 2013.

41 Ministério Público Federal/Acre, Processo 200830000045621: http://wrere.prac.mpf. mp.br/atos-do-mpf/acp/acphaitianos/view, petição inicial, p. 24.

42 Cançado Trindade, Antônio Augusto, "Dilemas e desafios da proteção internacional dos direitos humanos no limiar do século XXI", Revista Brasileira de Política Internacional [online], vol. 40, n. 1, 1997, pp. 167-177.

43 Sobre o número de vítimas da desnutrição grave e permanente: http://noticias.terra. com.br/ciencia/interna/0,OI1688154-EI298,00.html.

44 Apud Cunha, A. P., "O direito internacional dos refugiados em xeque: refugiados ambientais e econômicos", Revista Brasileira de Direito Internacional, Curitiba, vol. 8, n. 8, pp. 177-201, jul/dez 2008, 192.

D. R. (C) 2016. UNAM, Instituto de Investigaciones Jurídicas, Boletín Mexicano de Derecho Comparado, núm. 146, pp. 61-83. 
Esta revista forma parte del acervo de la Biblioteca Jurídica Virtual del Instituto de Investigaciones Jurídicas de la UNAM

resumido por Cunha ${ }^{45}$ "o refugiado econômico é movido pelo instinto de sobrevivência, enquanto o migrante, pelo desejo de melhorar suas condições de vida".

Esse é justamente o aspecto que, no trecho supracitado, a ação civil pública destaca. $\mathrm{O}$ que impele esses imigrantes haitianos de empreender uma viagem, muitas vezes ilegal e perigosa, até o Brasil, não é o simples desejo de melhorar de vida - como os migrantes econômicos-, mas a constatação de que nem mesmo dez anos de auxílio internacional, através, sobretudo, da MINUSTAH, foram capazes de garantir à grande parte da população a possibilidade de satisfação de suas necessidades vitais, como moradia, higiene, saúde, e, principalmente, água potável e comida. Eis, pois, um caso concreto de refugiado econômico. ${ }^{46}$

A gravidade da situação da fome no Haiti não precisa ser provada. É reconhecida pelo Programa Mundial de Alimentos (PNUMA), da ONU, cujos relatórios afirmam que:

... a insegurança alimentar é persistente no Haiti e atualmente um terço da população é considerada subnutrida; aproximadamente 600 mil pessoas precisam de assistência alimentar para sobreviver. Uma em cada 5 crianças sofre de desnutrição crônica, 6,5\% sofrem de desnutrição severa, enquanto mais da metade das mulheres e crianças sofrem de anemia. (tradução nossa). ${ }^{47}$

Ocorre que, tal como os migrantes ambientais, não há reconhecimento por parte do ACNUR da condição de refugiado econômico ou "refugiado da fome", como se convencionou tratar, apesar da Organização reconhecer a gravidade e a amplitude do problema. O termo surgiu em 2007 quando o suíço Jean Ziegler, relator por oito anos da Comissão de Direitos Humanos das Nações Unidas para o Direito à Alimentação, requereu, sem sucesso, ao Conselho de Direitos Humanos o reconhecimento dessa nova categoria. Por essa razão o Manual de Procedimentos do ACNUR cita expres-

45 Idem.

46 Zolberg, A. R. e Benda, P. M., Global Migrants, Global Refugees: Problems and Solutions, p. 45 .

47 "...Food insecurity is persistant in Haiti and today nearly a third of the population is considered food insecure; of those 600,00 need external food assistance to survive. Currently, one in every 5 children suffers from chronic malnutrition, $6,5 \%$ percent from acute malnutrition, while more than half of women and children suffer from anemia", http:// wrwe.wfp.org/countries/haiti/overview.

D. R. C 2016. UNAM, Instituto de Investigaciones Jurídicas, Boletín Mexicano de Derecho Comparado, núm. 146, pp. 61-83. 
Esta revista forma parte del acervo de la Biblioteca Jurídica Virtual del Instituto de Investigaciones Jurídicas de la UNAM

samente que a fome não se enquadra na definição de refúgio, uma vez que sua condição, a comprovação do fundado temor de perseguição não se encontra preenchida. Assim, o "fundado temor de perseguição... torna as outras razões da fuga irrelevantes para a definição", ${ }^{48}$ não importando sua gravidade ou urgência.

Todavia, ainda que o argumento do ACNUR seja sólido e válido em se tratando do reconhecimento do status de refugiado pele mundo, há duas questões que devem ser observadas no caso brasileiro e dos Estados sul-americanos. ${ }^{49}$

Em primeiro lugar, a Organização das Nações Unidas sempre fomentou a criação de organizações regionais, e a adaptação dos seus instrumentos de tutela jurídica internacional, incentivando os ajustes culturais, desde que respeitados os parâmetros mínimos dos instrumentos globais. Assim, no âmbito americano a Declaração de Cartagena de 1984 teve o objetivo de incorporar os princípios globais de proteção aos refugiados, mas levando-se em consideração as particularidades regionais, dentre elas as violações graves e generalizadas de direitos humanos. A partir de Cartagena os Estados Americanos tem se reunido a cada 10 anos para debater a questão, sempre tendo um fio condutor ou ponto de central de debates e ações.

Em 1994, em San José da Costa Rica, a Declaração de San José sobre Refugiados e Pessoas Deslocadas marcou o início dos debates sobre os deslocados internos no continente. Em 2004, na Cidade do México, o Plano de Ação do México para Fortalecer a Proteção Internacional dos Refugiados na América Latina insere, dentre as soluções duráveis, instrumentos de efetividade para o Reassentamento Solidário, a exemplo das cidades solidárias, e dá origem a uma estrutura solidária de acolhida de refugiados não apenas americanos em todos os Estados americanos, sobretudo no Brasil, que por suas características geopolíticas, de outro modo não seria um país de acolhida de refugiados palestinos, como ocor-

48 Manual de Procedimentos e critérios para a determinação da condição de refugiado, disponível em http://wrere.acnur.org/t3/fileadmin/scripts/doc.php? file =t3/fileadmin/Documentos/ portugues/Publicacoes/2013/Manual_de_procedimentos_e_criterios_para_a_determinacao_da_condicao_de_refugiado, p. 20.

49 Jubilut, Liliana Lyra e Apolinário, Silvia Menicucci de O. S., "Refugee Status Determination in Brazil: A Tripartite Enterprise", Refuge: Canada's Fournal on Refugees, 25, n. 2, 2008, p. 29. 
Esta revista forma parte del acervo de la Biblioteca Jurídica Virtual del Instituto de Investigaciones Jurídicas de la UNAM

reu. Em 2014, foi a vez do Brasil, que com o Marco de Cooperação e Solidariedade Internacional para Fortalecer a Proteção Internacional de Pessoas Refugiados, Deslocadas e Apátridas na América Latina e Caribe.

O marco de Cartagena, pois, foi impulsionar que os Estados americanos incorporassem em legislações nacionais próprias os princípios norteadores ali aprovados, trazendo para o plano doméstico as garantias de efetivação de direitos dos refugiados no continente. ${ }^{50}$

Assim ocorreu no Brasil e em outros Estados membros da UNASUL. No Brasil, o artigo $1^{\circ}$, III, da Lei n ${ }^{\circ}$ 9.474/97 não deixa dúvidas que, além dos requisitos defendidos pelo ACNUR para o reconhecimento do status de refugiados, encontra-se também a fuga de grave e generalizada violação de direitos humanos. ${ }^{51}$

Em segundo lugar, é importante destacar que não se pode negar que todos os haitianos, desde os que permaneceram no Haiti, por não terem condições de migrar, até aqueles que já se encontram no Brasil, detentores de visto humanitário, todos se enquadram na categoria de pessoas que fogem de graves e sistemáticas violações de direitos humanos, o que lhes garantiria, ao menos no Brasil, o reconhecimento do status de refugiado. ${ }^{52}$

A importância em se conferir o status de refugiado aos haitianos, ou a qualquer outra pessoa que preencha os requisitos legais, centra-se nas consequências e desdobramentos deste reconhecimento. O refugiado, assim reconhecido, não é apenas reconhecido como tal pelo Estado que o abriga, mas por toda comunidade internacional, goza de todos os direitos e deveres dos nacionais do país de acolhida, não podendo ser discriminado de forma alguma, detém status jurídico permanente e não se encontra a mercê da vontade política de governos ou de crises econômicas internacionais, como acontece com o asilo ou com os vistos, sejam eles de que natureza forem. ${ }^{53}$

50 Cançado Trindade, Antônio Augusto, "Dilemas e desafios da proteção internacional dos direitos humanos no limiar do século XXI”, pp. 167-177.

51 Savabi, Heidi, "The Legal Framework and Institutional Assistance for Refugees in Brazil since the Mid-Twentieth Century: The Impact on Refugee Integration and Assistance", p. 9.

52 Jubilut, Liliana Lyra e Apolinário, Silvia Menicucci de O. S., "Refugee Status Determination in Brazil: A Tripartite Enterprise on Refugees", p. 25.

53 Perusek, G., "Haitian Emigration in the Early Twentieth Century", International Migration Review, 18 (1), 1984, pp. 4-18.

D. R. (C) 2016. UNAM, Instituto de Investigaciones Jurídicas, Boletín Mexicano de Derecho Comparado, núm. 146, pp. 61-83. 
Esta revista forma parte del acervo de la Biblioteca Jurídica Virtual del Instituto de Investigaciones Jurídicas de la UNAM

Ainda, os refugiados que se encontram em fase de adaptação, ou seja, nos primeiros meses de ingresso no país de acolhida, fazem jus a ajuda de custo paga diretamente pelo ACNUR, a cursos de capacitação profissional e de idioma custeados pelo Estado receptor, além de integrarem a rede de refugiados no país, com todas as entidades da sociedade civil de atendimento cadastradas para auxiliá-los desde a busca por moradia até emprego. ${ }^{54}$

Os haitianos como foram recebidos com um visto humanitário, criação imprecisa e sem pouco fundamento jurídico, se assemelham aos asilados no Brasil, sem qualquer auxílio ou ajuda, à mercê do crime organizado e dos humores da política interna e externa de migrações, sendo constantemente discriminados e sofrendo no Brasil também violações graves e sistemáticas de direitos humanos. O perseguidor mudou de idioma, a violência não..$^{55}$

\section{CONSIDERAÇÕES FINAIS}

A situação dos haitianos no Brasil reflete o comportamento do país em face de sua política regional de integração: os discursos são bem diferentes da prática. A postura do Brasil em negar o reconhecimento do status de refugiado aos haitianos, ao tempo que concede sem critérios vistos de trabalho ${ }^{56}$ e de residência permanente aos europeus ${ }^{57}$ que fogem da crise econômica

54 Moreira, Julia Bertino e Baeninger, Rosana, "Local Integration of Refugees in Brazil", Forced Migration Review, n. 35, 2010, p. 48.

55 Rosa, Renata de Melo, "Xenofobização da mulher negra migrante no processo de construção do feminino em emigração: a migração feminina haitiana em Santo Domingo", Revista Interdisciplinar da Mobilidade Humana, 15 (29), 2007, pp. 71-86.

56 "Portugueses são os estrangeiros que mais foram agraciados com vistos de trabalho no Brasil em 2012", http://wrere.jn.pt/PaginaInicial/Sociedade/Interioraspx?'content_ $i d=3024905$.

57 "Em 2012 o Brasil concedeu 73 mil vistos de trabalho a estrangeiros. Portugal, Espanha e China foram as nacionalidades mais beneficiadas por esses vistos. Houve aumento de $81 \%$ no número de vistos emitidos a portugueses com relação a 2011 , de $53 \%$ a espanhóis e de $24 \%$ a chineses... Os dados também demonstram o impacto da concessão de residências especiais de caráter humanitário pelo Conselho Nacional de Imigração (CNIg) aos haitianos, com 4.706 autorizações expedidas em 2012. Na avaliação dos técnicos, a situação é transitória e emergencial, tendo impacto importante já que são autorizações especiais e de viés humanitário em relação ao agravamento da situação recente do Haiti 
Esta revista forma parte del acervo de la Biblioteca Jurídica Virtual del Instituto de Investigaciones Jurídicas de la UNAM

na Europa, demonstra como a herança colonial ainda se faz presente e vívida no maior país da América do Sul.

Por ocasião do aniversário de 30 anos da Declaração de Cartagena (1984), os Estados americanos se preparam para celebrar, em Brasília, neste ano de 2014, o marco Cartagena+30. O Brasil que vai sediar o evento tem propostas de reiterar os compromissos assumidos em Cartagena, de ampliar o programa de reassentamento solidário e já declarou que irá doar 3,1 milhões de dólares para o ACNUR para fomentar a recepção de refugiados colombianos e congoleses no Brasil. ${ }^{58}$

Os discursos no âmbito político, todavia, não vem acompanhado da práxis jurídica. O caso dos haitianos no Brasil bem exemplifica o fato. No que tange aos Estados-membros da UNASUL, majoritariamente também partes da Declaração de Cartagena, os reflexos da postura brasileira são o aumento da atuação de organizações criminosas em seus territórios, o enfraquecimento da segurança em suas fronteiras, e o aumento do número de refugiados haitianos que, sem conseguir chegar ao Brasil, requerem refúgio pelo caminho, sobrecarregando Estados menores em extensão territorial, em desenvolvimento econômico e oportunidades de emprego, a exemplo do Equador.

O discurso de integração, cooperação e solidariedade internacional do Brasil não reflete sua política de imigração, que se assemelha às praticadas por Estados Unidos e União Européia, demonstrando que o Brasil adota postura imperialista no continente que visa integrar por razões não apenas econômicas, mas se segurança regional e fortalecimento histórico-cultural. ${ }^{59}$

após o terremoto de 2010, mas que não devem se refletir no longo prazo", http://portal.mte. gov.br/imprensa/brasil-concedeu-73-mil-vistos-de-trabalho-a-estrangeiros-em-2012.htm

58 "O Brasil declarou que vai doar 3,1 milhões de dólares para o Acnur em dois projetos-piloto para ampliar seu atual programa de reassentamento: um para estimular a migração de colombianos voltada especificamente ao trabalho, com aulas de português, orientação para o mercado de trabalho e ajuda financeira por três meses, e outro para o reassentamento de jovens congoleses. O Equador é o país com a maior população refugiada do continente: são 55 mil pessoas, entre as quais apenas $2 \%$ não são colombianas". http://wrew.justica.gov.br/noticias/paises-andinos-se-preparam-para-encontro-em-brasilia-sobre-re fugiados.

59 Arruda, Aline Maria Thomé, "Migração e refúgio: uma breve problematização sobre os direcionamentos governamentais para recepção a haitianos no Brasil e na Repúbli- 
Esta revista forma parte del acervo de la Biblioteca Jurídica Virtual del Instituto de Investigaciones Jurídicas de la UNAM

Aos Estados-membros da UNASUL, ao se reunirem em Brasília neste novembro próximo, cabe exigir do Brasil uma posição mais séria e condizente com o fenômeno migratório que acomete o continente nesta segunda década do século XXI. Integrar é também dividir os ônus do processo. Na alegria e na tristeza, na riqueza e na pobreza, até que todos sejam salvos da morte por desnutrição. Em um mundo cuja quantidade de comida produzida é suficiente para alimentar, com 2,7 mil calorias diárias, o dobro da população mundial, uma criança morre de fome a cada 5 segundo. ${ }^{60}$ E o que o Brasil tem a ver com isso? Muitas dessas crianças são haitianas. ${ }^{61}$

Se lograr êxito, a ação civil pública proposta pelo Ministério Público do Acre refletirá em todo o continente sul-americano. O reconhecimento, ainda que compulsório, por parte do Brasil de que sim catástrofes ambientais e miséria extrema são condições de refúgio poderá equilibrar a balança de migrações no continente, tornando os Estados-membros da UNASUL sim, integrados, por motivos humanitários. ${ }^{62}$

\section{REFERÊNCIAS DAS FONTES CITADAS}

AGnUR, Manual de Procedimentos e critérios para a determinação da condição de refugiado, disponível em http://wrwreacnur.org/t3/fileadmin/ scripts /doc.php? file $=t 3 /$ fileadmin $/$ Documentos $/$ portugues $/$ Publicacoes $/ 2013 /$ Manual_de_procedimentos_e_criterios_para_a_determinacao_da_condicao_de_ refugiado.

ARRUDA, Aline Maria Thomé, "Migração e refúgio: uma breve problematização sobre os direcionamentos governamentais para recepção a haitianos no Brasil e na República Dominicana", Universitas Relações Internacionais, Brasília, v. 11, n. 1, pp. 105-111, jan./jun. 2013.

ca Dominicana", Universitas Relações Internacionais, Brasília, vol. 11, n. 1, jan./jun. 2013, pp. 105-111.

60 Fonte: Relatório Anual da FAO (agência da ONU para alimentação e agricultura), 2012. Dados disponíveis em http://wwre.carosamigos.com.br/index.php/component/content/ article/225-revista/edicao-195/3327-jean-ziegler-a-fome-que-o-capitalismo-sustenta-por-aray-nabuco-fredi-vasconcelos-e-lilian-primi.

61 Feldmann, A. E., "Haiti's 'Phantom Ghost State", Migraziones Forzadas, Refugee Studies Centre, University of Oxford, UK, July: 2013, pp. 32-34.

62 Patarra, N. L., O Brasil: país de imigração?, p. 18. 
Esta revista forma parte del acervo de la Biblioteca Jurídica Virtual del Instituto de Investigaciones Jurídicas de la UNAM

Cançado Trindade, Antônio Augusto, "Dilemas e desafios da proteção internacional dos direitos humanos no limiar do século XXI", Revista Brasileira de Política Internacional [online], vol. 40, n. 1, 1997.

Cunha, A. P., "O Direito Internacional dos refugiados em xeque: refugiados ambientais e econômicos", Revista Brasileira de Direito Internacional, Curitiba, v. 8, n.8, jul/dez 2008.

Feldmann, A. E., "Haiti's 'Phantom Ghost State", Migraziones Forzadas, Refugee Studies Centre, University of Oxford, UK, july: 32-34, 2013.

FERnANDES, Jéssica S., "Operação Haiti: ação humanitária ou interesse político para o Brasil?”, Conjuntura internacional, PUC Minas, 22 March: 1-4. Published on line, 22 march 2010: http:/wrere.pucminas.br/conjuntura. Accessed 19 April 2011.

JubILUT, Liliana Lyra, "Refugee Law and Protection in Brazil: A Model in South America?", Journal of Refugee Studies 19, núm. 1, n. 38, 2006. e Apolinário, Silvia Menicucci de O. S, "Refugee Status Determination in Brazil: A Tripartite Enterprise", Refuge: Canada's Journal on Refugees 25, núm. 2, 2008.

Martin, P. e Midgley, E. et al., "Migration and development: whiter the Dominican Republic and Haiti?", International Migration Review, Center for Migration Studies of New York, 36 (2), Summer: 570-592, 2002.

Melo Rosa, Renata de, "Xenofobização da mulher negra migrante no processo de construção do feminino em emigração: a migração feminina haitiana em Santo Domingo", Revista Interdisciplinar da Mobilidade Humana, 15 (29): 71-86, 2007.

"A construção da desigualdade no Haiti: experiências históricas e situações atuais", Revista Universitas: Relações Internacionais, v. 4, n. 2, 2006.

MoreirA, Julia Bertino e BAEninger, Rosana, "Local Integration of Refugees in Brazil", Forced Migration Review, n. 35 , 2010.

ONU, United Nation Treaty Collection. https://treaties.un.org/pages/View-

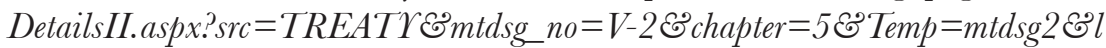
ang $=e$.

PATARRA, N. L., “O Brasil: país de imigração?”, Metropolis, Revista Eletrônica de Estudos Urbanos e Regionais, (9) 3: 6-18, 2012.

PAULA, Bruna Vieira de, O princípio do non-refoulement, sua natureza jus cogens e a proteção internacional dos refugiados, Corte Interamericana de Direitos 
Esta revista forma parte del acervo de la Biblioteca Jurídica Virtual del Instituto de Investigaciones Jurídicas de la UNAM

Humanos, 2006. Acesso em 11/09/2014. http://wrere.corteidh.or.cr/tablas/r28151.pdf.

PentinAT, S. B., "El estatuto jurídico de protección internacional de los refugiados ambientales", Revista Interdisciplinar da Mobilidade Humana, (19) 36: 11-48, 2011.

RAMÍREZ, A., "ONU pede mais proteção para refugiados ambientais", entrevista (25 de maio, 2012). Observatório Eco. Disponível em wrere.observatorioeco.com.br/onu-pede-mais-protecao-para-refugiados-ambien tais $/+\mathcal{E}^{2} c d=3 \mathcal{E}^{2} h l=p t-B R \mathcal{E}^{2} c t=c \operatorname{lnk} \mathcal{E}^{2} g l=b r \mathcal{E} l r=l a n g \_f r \% 7$ Clang_en $\% 7$ Clang_pt. Acesso em 08/02/2014.

RAMOS, E., Refugiados ambientais: em busca de reconhecimento pelo direito internacional, 2011, tese (doutorado em direito), Faculdade de Direito, Universidade de São Paulo, São Paulo, 2011.

Richman, K., "A More Powerful Sorcerer: Conversion, Capital, and Haitian Transnational Migration", New West Indian Guide, 82(1-2): 3-45, 2008.

ROCHA REIS, R., "A política do Brasil para as migrações internacionais", Contexto Internacional, 33(1): 47-69, 2011.

PeruseK, G., "Haitian Emigration in the Early Twentieth Century", International Migration Review, 18 (1): 4-18, 1984.

SAVABI, Heidi, "The Legal Framework and Institutional Assistance for Refugees in Brazil since the Mid-Twentieth Century: The Impact on Refugee Integration and Assistance", IMTP-Magazine on Migration Issues, Summer 2014.

SEITENFUs, Ricardo, Haiti: dilemas e fracassos internacionais, Ijuí, Unijuí, 2014.

SILvA, Sidney Antonio, "Brazil, a new Eldorado for immigrants?: The case of Haitians and the Brazilian Immigration Policy", Urbanities, vol. 3, n. 2, november, 2013.

TAMER, Alexandre dos Santos e POzzeti, Valmir César, "A imigração haitiana e a criminalidade no Município de Manaus", Revista do Direito Público. Londrina, vol. 8, n. 3, set./dez. 2013.

TÉLÉMAQUE, Jenny, Imigração haitiana na mídia brasileira: entre fatos e representações, 2012, monografia apresentada ao final do curso de Jornalismo-Escola de Comunicação, Centro de Filosofia e Ciências Humanas, Universidade Federal do Rio de Janeiro, Rio de Janeiro. 
ThomAZ, Diana Zacca, "Migração haitiana para o Brasil pós-terremoto: indefinição normativa e implicações políticas", Primeiros Estudos, São Paulo, n. 4, 2013.

Thomaz, Omar Ribeiro, "O terremoto no Haiti, o mundo dos brancos e o Lougawou”, Novos Estudos, São Paulo, vol. 1, n. 86, mar. 2010.

Zeferino, Marco Aurélio Pieri e Aguado, Juventude de Castro, "Os deslocamentos ambientais para o Brasil", Revista SFRF, Rio de Janeiro, vol. 19, n. 35, dez. 2012.

Zolberg, A. R. y BendA, P. M., Global Migrants, Global Refugees: Problems and Solutions, Washington (D. C.), Berghahm Books, 2001. 